\title{
Moving the pain education agenda forward: Innovative models
}

\author{
Judy Watt-Watson RN MSc PhD, Eloise Carr BSc(Hons) RN PGCEA RNT MSc PhD, Michael H McGillion RN PhD
}

$\mathrm{U}$ nrelieved acute and persistent pain is a widespread global problem for divergent patient groups across the lifespan. Although pain education has been identified as a strategy to improve ineffective pain management practices (1), recent evidence supports the continuing lack of pain content in health science curricula, particularly for prelicensure students in Canada and the United Kingdom (2,3). Comprehensive pain assessment and management are essential to reduce the prevalence and burden of pain, and new strategies are required to support these changes.

This collection of articles focuses on the worldwide prevalence of the problem, education initiatives at the international level, and examples of the latest developments in educational methods and pedagogy relevant to moving the global pain education agenda forward. The authors bring expertise that represents both international and Canadian thinking.

These articles were selected from presentations given August 26 to 27, 2010, at the first International Pain Education Satellite Symposium held in Toronto, Ontario, in conjunction with the International Association for the Study of Pain (IASP) 13th World Congress on Pain. Feedback from more than 90 participants from 12 countries indicated that they found these presentations enlightening and helpful. This satellite symposium helped to crystallize previous efforts to establish the IASP Pain Education Special Interest Group, subsequently approved in Montreal, Quebec, in September 2010. The contributing authors are recognized innovative thinkers in their fields, and stimulate ideas about new models of pain education. The aim of the current issue is to provide a resource to anyone involved or hoping to be involved in the future of pain education.

\section{REFERENCES}

1. Sessle B. Incoming President's address: Looking back, looking forward. In: Devor M, Rowbotham MC, Wisenfield-Hallin Z, eds. Progress in Pain Research and Management, Proceedings of the 9th World Congress on Pain; 1999 August 22 to 27, Vienna, Austria. Seattle: IASP Press, 2000:16:9-18.

2. Watt-Watson J, McGillion M, Hunter J, et al. A survey of prelicensure pain curricula in health science faculties in Canadian universities. Pain Res Manag 2009;14:439-44.

3. Briggs E, Carr ECJ, Whittaker M. Survey of undergraduate pain curricula for healthcare professionals in the United Kingdom. Eur J Pain 2011;15:789-95. 


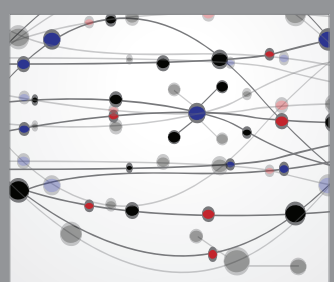

The Scientific World Journal
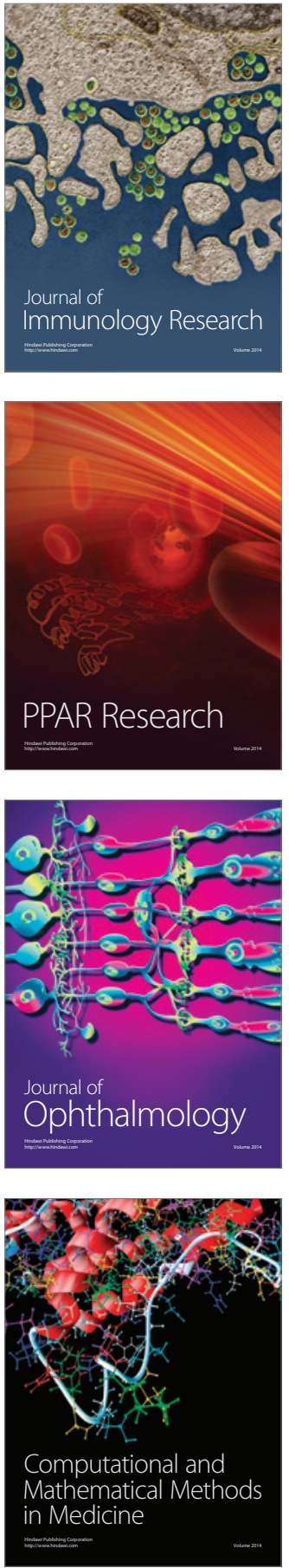

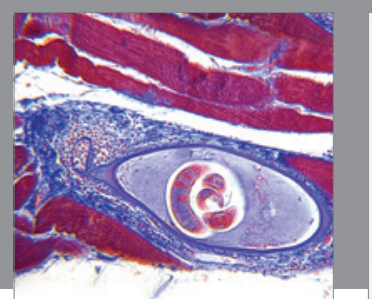

Gastroenterology Research and Practice

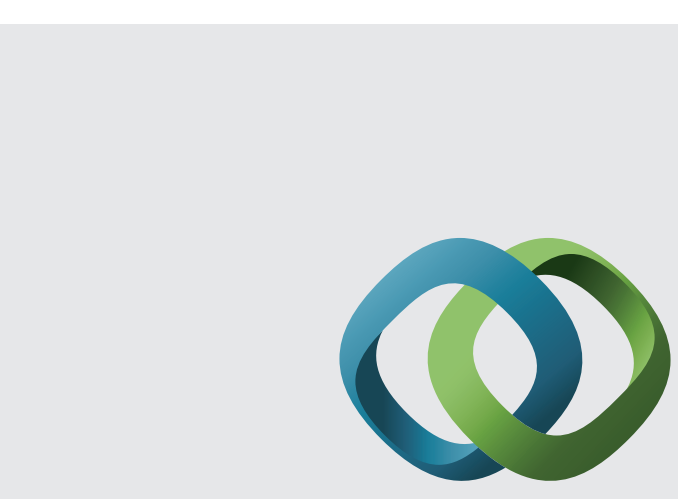

\section{Hindawi}

Submit your manuscripts at

http://www.hindawi.com
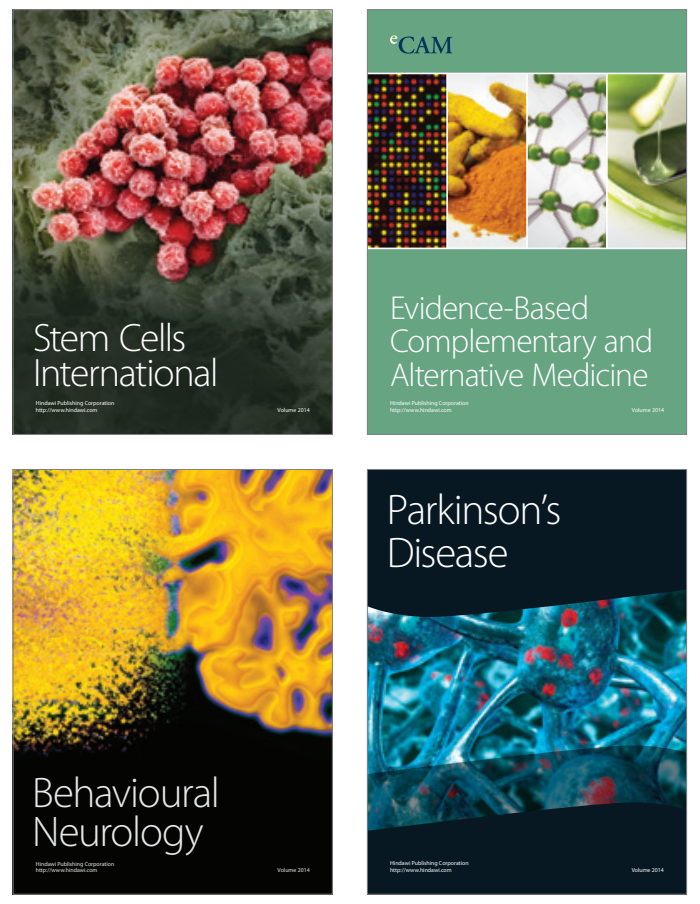
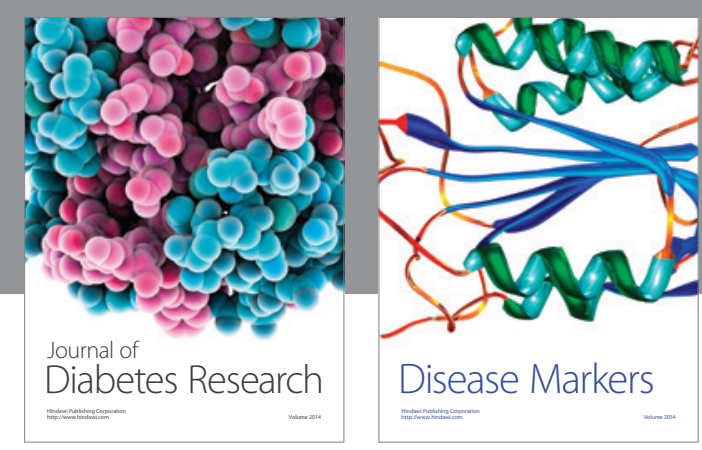

Disease Markers
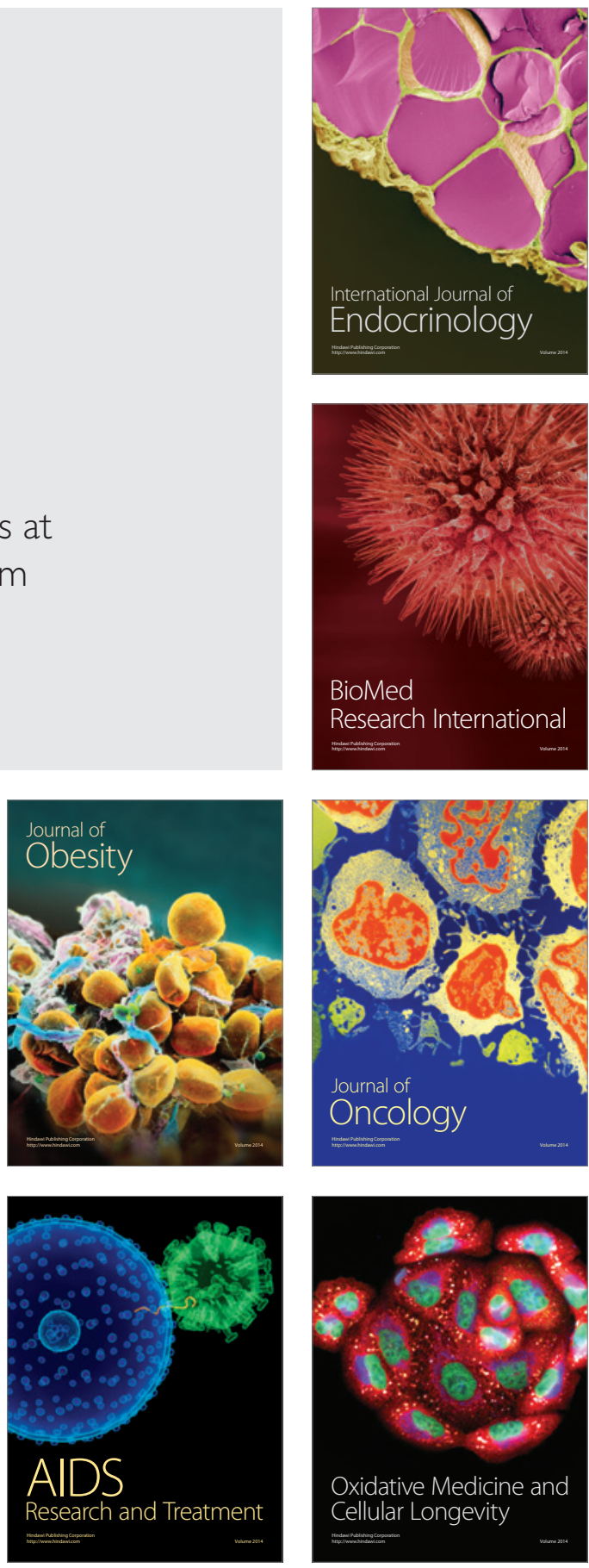